\title{
ANASTOMOTIC SURVIVAL DESPITE DUAL MESENTERIC ARTERIAL THROMBOSIS: A CASE REPORT
}

Durairaj Balaji ${ }^{1}$, Arun Prasanth², Alankrith Ramesh Kashyap ${ }^{3}$, Mohamed Musthafa ${ }^{4}$, Parivallal Damodaran ${ }^{5}$

${ }^{1}$ Assistant Professor, Department of General Surgery, SRM Medical College, Hospital \& Research Centre, Chennai.

2Postgraduate, Department of General Surgery, SRM Medical College, Hospital \& Research Centre, Chennai.

3 Postgraduate, Department of General Surgery, SRM Medical College, Hospital \& Research Centre, Chennai.

${ }^{4}$ Professor, Department of General Surgery, SRM Medical College, Hospital \& Research Centre, Chennai.

5 Postgraduate, Department of General Surgery, SRM Medical College, Hospital \& Research Centre, Chennai.

\section{ABSTRACT}

Usually, in acute on chronic mesenteric ischaemia, the safest option is resection of infarcted bowel and exteriorisation of both ends. This allows inspection of both bowel ends for their viability. Anastomosis and restoration of continuity of bowel is delayed for 4-6 months is done in favour of healing. If the viability of bowel is unclear, second look laparotomy maybe needed, which may maximize intestinal salvage. In this case, we have done massive resection of small bowel with end-to-end anastomosis, which survived in spite of more than $50 \%$ thrombosis of two major vessels.

\section{KEYWORDS}

Superior Mesenteric Artery (SMA) Thrombosis, Inferior Mesenteric Artery (IMA) Thrombosis, Acute Arterial Mesenteric Ischaemia.

HOW TO CITE THIS ARTICLE: Balaji D, Prasanth A, Kashyap AR, et al. Anastomotic survival despite dual mesenteric arterial thrombosis: a case report. J. Evolution Med. Dent. Sci. 2016;5(68):4935-4936, DOI: 10.14260/jemds/2016/1120

\section{INTRODUCTION}

In longstanding atherosclerotic disease two or more mesenteric vessels leads to Chronic Mesenteric Ischaemia. Acute thromboembolic occlusion of superior mesenteric artery is an uncommon occurrence in hospital that comprise $0.1 \%$ hospital admissions.[1] Despite all treatment it has a poor prognosis with mortality rate of $59 \%$ to $93 \%$. Incidence of SMAT has been estimated to be 5.3/100000 person per year.[2] Bowel Ischaemia can be classified as thrombotic or nonthrombotic events. Specific thrombotic conditions include Superior Mesenteric Arterial Embolisation (SMAE), Arterial Thrombosis (SMAT) and Mesenteric Venous Thrombosis (MVT).[3] When patient is presented in less than 12 hours, early intervention is essential for intestinal viability.

\section{CASE REPORT}

A 47-year-old male presented with complaints of abdominal distension, vomiting and features of intestinal occlusion. Computed tomography scan of abdomen showed features of small bowel obstruction. Laparotomy was done under general anaesthesia. Massive small bowel gangrene was visualised 80 $\mathrm{cm}$ from duodenojejunal flexure up to $20 \mathrm{~cm}$ before ileocaecal junction (Figure 1). Resection and Anastomosis of necrotic bowel was done. Resected segments were sent for histopathological study, which showed areas of congestion. Necrosis and transmural infarct in all layers with gangrenous small bowel. Postoperatively, patient underwent contrast enhanced angiography, which revealed $60 \%-70 \%$ stenosis of proximal superior mesenteric artery and $80-90 \%$ thrombotic occlusion of proximal inferior mesenteric artery with complete thrombotic occlusion of left common iliac artery (Figure 2 and Figure 3). Patient was given intensive care and treated with low molecular weight heparin and ralidex

\footnotetext{
Financial or Other, Competing Interest: None.

Submission 18-07-2016, Peer Review 12-08-2016,

Acceptance 17-08-2016, Published 25-08-2016.

Corresponding Author:

Dr. Alankrith Ramesh Kashyap,

Room 303, PG Medical Gents Hostel,

SRM College Hospital \& Research Centre,

SRM Nagar, Kattankulathur, Chennai-603203.

E-mail: koolchant@gmail.com

DOI: $10.14260 /$ jemds $/ 2016 / 1120$
}

(Dextran, dextrose and sodium chloride) solution to maintain the volume of blood plasma. On $14^{\text {th }}$ postoperative day, patient was discharged without any complications.

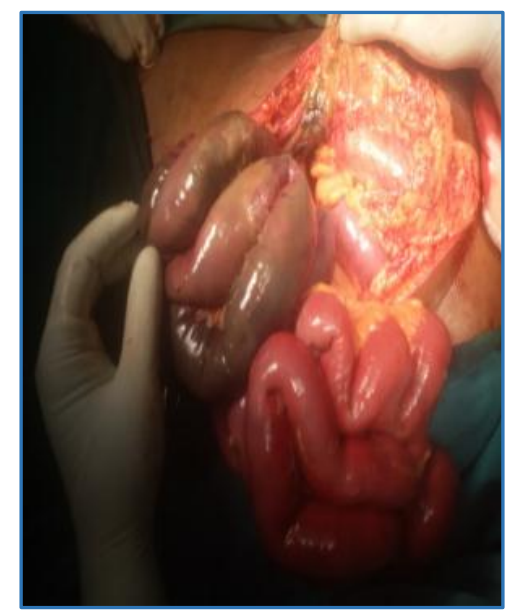

Fig. 1: Laparotomy Finding showing Massive Small Bowel Gangrene

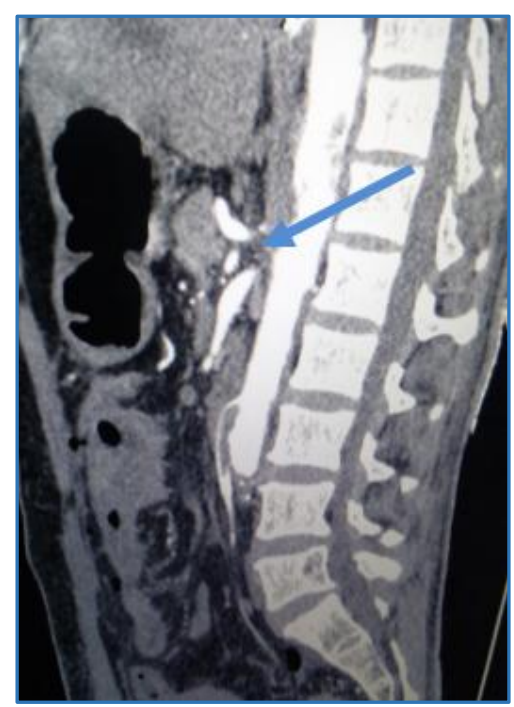

Fig. 2: CT-Angio showing Proximal Superior Mesenteric Artery Stenosis 


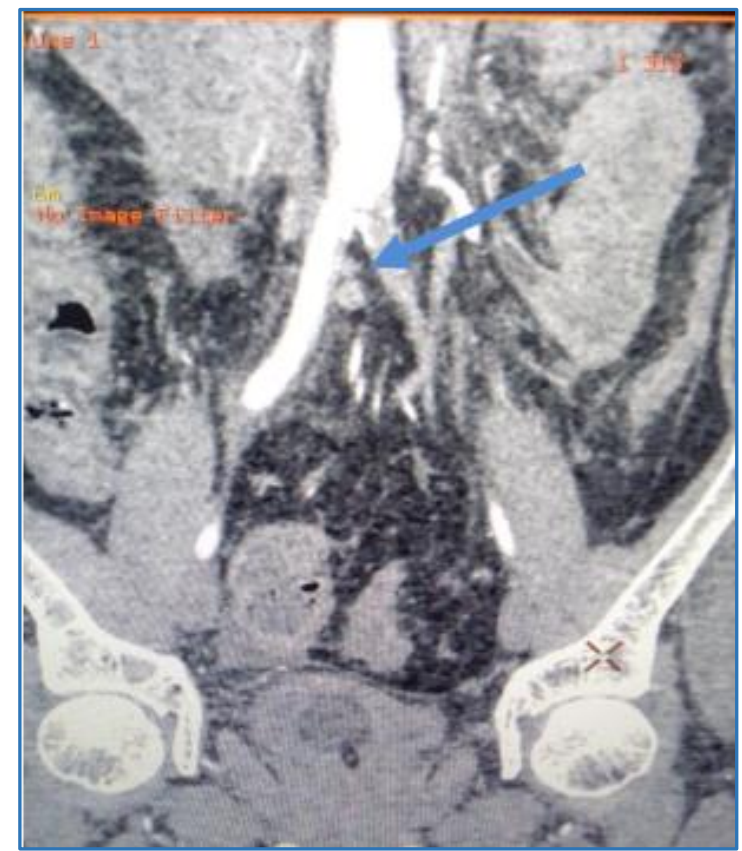

Fig. 3: CT-Angio showing Complete Thrombotic Occlusion of Left Common Iliac Artery with Length of $72 \mathrm{~mm}$

\section{DISCUSSION}

Acute Mesenteric Ischaemia is a result of a sudden occlusion of the proximal portion of the major mesenteric arterial supply usually due to embolus or thrombus. The incidence of significant acute mesenteric ischaemia is due to arterial embolus (50\%) and arterial thrombus (20\%). Most commonly embolus is seen in superior mesenteric artery, because of its more favourable angle with the aorta rather than celiac artery or inferior mesenteric artery. Typically, embolus lodges at the major branch distal to the middle colic artery, preserving the blood supply of transverse colon and proximal jejunum. ${ }^{[4]}$

Most common risk factors are history of vasculitis of Beurger's disease, cardiac arrhythmias, acute myocardial infarction, history of previous embolic event, recent heparin or warfarin treatment, atherosclerosis. Ischaemia occurs due to sudden decrease in blood flow to meet the metabolic demands of the abdominal viscera.

Diagnosis of acute mesenteric ischaemia can be made out by duplex ultrasonography and CT angiography. Gold standard method is contrast enhanced Magnetic Resonance Arteriography.[5]

Acute arterial thrombosis superimposed on pre-existing severe atherosclerotic disease accounts for $25 \%$ to $30 \%$ of all cases.[6] Time taken for infarction of bowel is more insidious because of increased collateral blood supply, which maintain viability until there is a final closure of severely ill stenotic vessel or collateral. The infarction is more confluent without sparing of small bowel or right colon circulation. The small bowel is able to endure a significant reduction in blood flow. However, when the ischaemia is prolonged, it leads to dissipation of the intestinal mucosa, which then leads to gangrene.

The main aim of the surgery is to look for extent of bowel damage and flow of mesenteric arteries.[3] If there is necrosis of bowel, surgical resection of the gangrenous bowel should be done. Second look laparotomy should be planned 2-36 hours later to assess bowel viability and anastomotic leak. In a less emergency situation, if angiography shows localised thrombus or embolus, intra-arterial thrombolysis, percutaneous aspiration thrombectomy with or without balloon angioplasty and adjunctive stenting can be done.

Recent studies conducted for additional therapeutic possibilities include the use of heparin-binding epithelial growth factor to protect the intestines and other organs from ischaemic injury, percutaneous transluminal angioplasty, tolazoline and nitroglycerin as interarterial infusions. ${ }^{[7,8]}$

\section{CONCLUSION}

In summary, mesenteric ischaemia is a challenging clinical problem with host of causes, often diagnosed late and a strong clinical suspicion remains the key to early diagnosis. In the acute form an aggressive approach should be adopted because the outcome crucially depends on rapid diagnosis and treatment; on the other hand in chronic cases the therapeutic decision should be carefully made balancing risks and benefits, considering other comorbidities.

The dictum in cases of acute on chronic mesenteric ischaemia is resection of the affected part of bowel with the blind loops exteriorized as stomas to facilitate regular inspection of bowel ends for viability. Following a delay period of 4-6 months, during which healing of affected bowel segments takes place anastomosis and restoration of exteriorized bowel is done, which includes a second look laparotomy in case of unviability to maximize intestinal salvage.

In this case of a 47-year-old male who was diagnosed as acute on chronic mesenteric ischaemia with massive bowel gangrene, who underwent massive resection and end-to-end anastomosis of small bowel survived in spite of more than $50 \%$ stenosis and thrombotic occlusion of Superior Mesenteric Artery and Inferior Mesenteric Artery. Anastomotic survival followed by massive resection of bowel with thrombosis is very rare and so this case is presented for its rarity.

\section{REFERENCES}

1. Kozuch PL, Brandt LJ. Review article: diagnosis and management of mesenteric ischemia with an emphasis on pharmacotherapy. Aliment Pharmacol Ther 2005;21(3):201-15.

2. Acosta $S$, Björck M. Acute thromboembolic occlusion of the superior mesenteric artery: a prospective study in a well-defined population. Eur J Vasc Endovasc Surg 2003;26(2):179-83.

3. Endean ED, Barnes SL, Kwolek CJ, et al. Surgical management of thrombotic acute intestinal ischemia. Ann Surg 2001;233(6):801-8.

4. Boley SJ, Brandt LJ, Sammartano RJ. History of mesenteric ischemia: the evolution of a diagnosis and management. Surg Clin North Am 1977;77(2):275-88.

5. Baden JG, Racy DJ, Grist TM. Contrast-enhanced threedimensional magnetic resonance angiography of the mesenteric vasculature. J Magn Reson Imaging 1999;10(3):369-75.

6. Lock G. Acute intestinal ischaemia. Best Pract Res Clin Gastroeterol 2001;15(1):83-98.

7. James IA, Chen CL, Huang G, et al. HB-egf protects the lungs after intestinal ischemia/reperfusion injury. J Surg Res 2010;163(1):86-95.

8. Cortese B, Limbruno B. Acute mesenteric ischemia: primary percutaneous therapy. Catheter Cardiovasc Interv 2010;75(2):283-5. 